\title{
Onang-onang: Angkola Mandailing Oral Tradition (Viewed from Culture, Local Wisdom and Education Perspectives)
}

\author{
Roswita Silalahi', Ely Hayati Nasution², Anna Leli Harahap ${ }^{3}$ \\ 1), 2) English Department, Faculty of Cultural Sciences \\ University of Sumatera Utara Medan Indonesia, University of Graha Nusantara Padangsidimpuan, Sumatera \\ Utara \\ Medan, Indonesia \\ roswita_silalahi@yahoo.com
}

\begin{abstract}
Empowering local culture to sustain local wisdom has become a crucial issue since the publication of President Decree No. 5 the year 2017, emphasizing on the significance of enhancing culture in all aspects, and included education. This paper aims to investigate Onang-Aonang, an Angkola Mandailing oral tradition viewed from culture, local wisdom and education perspectives. This research was the combination of library and field research. The research applied qualitative descriptive method supported by documentation, interview and focus group discussion (FGD). The text of Onang-onang uttered by the old during Manortor ( a traditional dance performed at wedding ceremony) was selected as the main data and the attributes used (colored flags, musical instruments, and clothes) were treated as the additional data. The main data next was translated into Bahasa Indonesia (Larson, 1998) and then was analyzed in order to find out the local wisdom values (Sibarani, 2012) and the character education concepts (Muchlas and Hariyanto, 2011) by correlating them with the additional data. The research found Onang-onang represented three main perspectives; the culture itself (custom and kinship system), local wisdom values (obedience, equality, respect, being humble, togetherness and carefulness) and education concepts (preserving tradition and the family role).
\end{abstract}

Keywords-Onang-onang; culture; local wisdom; character education

\section{INTRODUCTION}

Mandailing is a traditional cultural group mainly living in the northern section of Sumatera Island, Indonesia. It is divided into 2 (two) major regions, namely Mandailing Godang (Mandailing Besar; living around agricultural areas and Mandailing Julu/Ulu (Mandailing Hulu/Kecil); living around plantation areas [4]. The Mandailing were associated with the Toba Batak people instead of being recognized as a distinct ethnic minority. Consequently, they are identified between two cultural and ethnic identities, Angkola-Mandailing and Batak-Mandailing.

Mandailing community, like other Batak tribes, is patriarchal, employing family names or marga (for male) and Boru (for female). There are only elevens of them; Siregar, Hasibuan, Harahap, Dalimunthe, Matondang, Rangkuti, Parinduri, Pulungan, Rambe, Daulay, Pohan, Batubara, Barus, Hutajulu, Nasution, and Lubis. Nasution and Lubis are considered as the biggest groups in Mandailing clan. The mandailingnese family is categorized as extended family. There will be other family members living together with the nuclear family, for instance, grandparents (opung). Therefore, any custom activities always involve the whole family members, for example, wedding ceremony.
The wedding ceremony is one main traditional ceremony carried on Mandailing community as it will add the number of family members (the family binding/line), not only the bridegroom themselves. Moreover, there will be a sequence of events to be done during the procession and certainly, it requires the participation of all. One of them is manortor (dancing). It is danced by all the people attending the ceremony; young to old, men and women, even rich and poor. Manortor is an obligatory; an expression to show the cheerful and happiness; and also a way to gather and educate, especially for the youngsters through the lyrics uttered by the old during manortor familiarly known as onang-onang.

Onang-onang is a kind of Mandailingnese oral tradition as well as literature (folklore). It contains lyrics as a song uttered during manortor. The lyric itself shows the social status (the position in kinship system) of the dancers but with the same melody. It also conveys hopes and advises to the Mandailing to behave properly, particularly the bridegroom. It implies that its lyrics represent the local wisdom embracing on the Mandailing community, as [5] defined that the local wisdom is the value of local culture, having been applied to wisely manage the community's social order and social life. The way onang-onang performed, the attributes used and 
the lessons acquired, are very interesting to be analyzed, mainly in this globalization era. Therefore, this paper aims to analyze onangonang viewed from culture, local wisdom and education perspectives.

\section{METHOD}

This research was the combination of library and field research. The research applied qualitative descriptive method supported by documentation, interview and focus group discussion (FGD). The text of Onang-onang uttered by the old during Manortor ( a traditional dance performed at wedding ceremony) was selected as the main data and the attributes used (coloured flags, musical instruments, and cloth) were treated as the additional data. The main data next was translated into Bahasa Indonesia (Larson, 1998) and then was analysed in order to find out the local wisdom values (Sibarani, 2012) and the character education concepts (Muchlas and Hariyanto, 2011) by correlating them with the additional data.

\section{FINDINGS AND DISCUSSIONS}

The results of the research are categorized into 3 (three) parts, they are: 1) culture perspective, 2) local wisdom perspective, and 3) education perspective.

\section{A. Culture Perspective}

Language is one of culture elements functions as a verbal expression of language, as [3] stated that there are 7 (seven) elements of culture: language, knowledge system, social organization, living system equipment and technology, livelihood system of life, religion system, and arts. Language is considered as the prior aspect analysed in the research in order to find out the 3 (three) perspectives. The culture perspective itself is reflected through lyrics expressed by the old in onang-onang and the attributes used during manortor. Culturally, there are 2 (two) important things obtained related to onangonang lyrics, namely: custom and kinship system.

\section{1) Custom}

There are 4 (four) kinds of tortor performed: tor-tor raja-raja/namora-mora (for the old and prominent figures danced by their wives); tor-tor andor soayu (for married men and women); tortor naposo bulung/nauli bulung (for youngsters) and tortor pengantin (for bridegroom; the closing dance). Each tor-tor as well as its attributes have certain rules that must be followed. Generally, tor-tor is done in alaman na bolak (large field) as it is attended by many people, occupied with a cow, bendera napitu or bendera tonggol (seven colured flags), gondang dua (two drums), two cenang (two small gongs), two gongs (the big one) and a flute. According to the interview done with the expert, Mr. Ali Akbar Siregar (harajaon namora-mora of the groom) and Mrs. Siti Roma (kahanggi), it is obtained that cow is used to sign that the ceremony will be started; seven coloured flags (white, black, red, yellow, gree) also convey meanings; white for purity, black for power, red for braveness,green for faith, yellow for peace; and for the musical instruments used; two drums are played by four persons, each drum is oppositely played by two drummers, two gongs and two cenang are the same, the right one (louder) is gong/cenang jantan (for male) and the left one is gong/cenang boru (for female). During manortor, the players (pargondang or paruning-uningan) wear traditional costumes while the dancers must put on the ulos. They also must dance in pairs, as illustrated in the followings:.

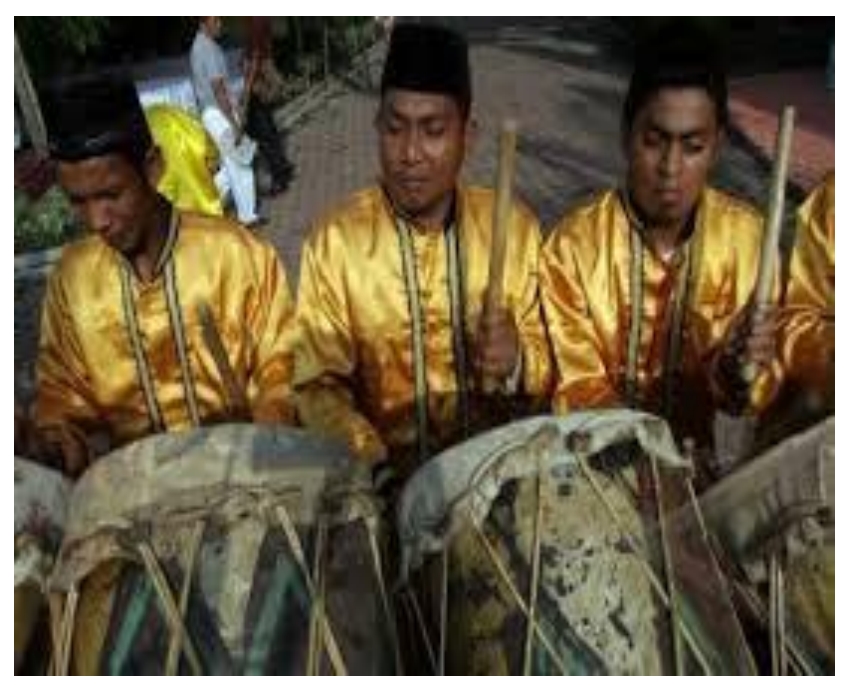

Figure 1. The Musical Instruments Used for Escorting Onang-onang 


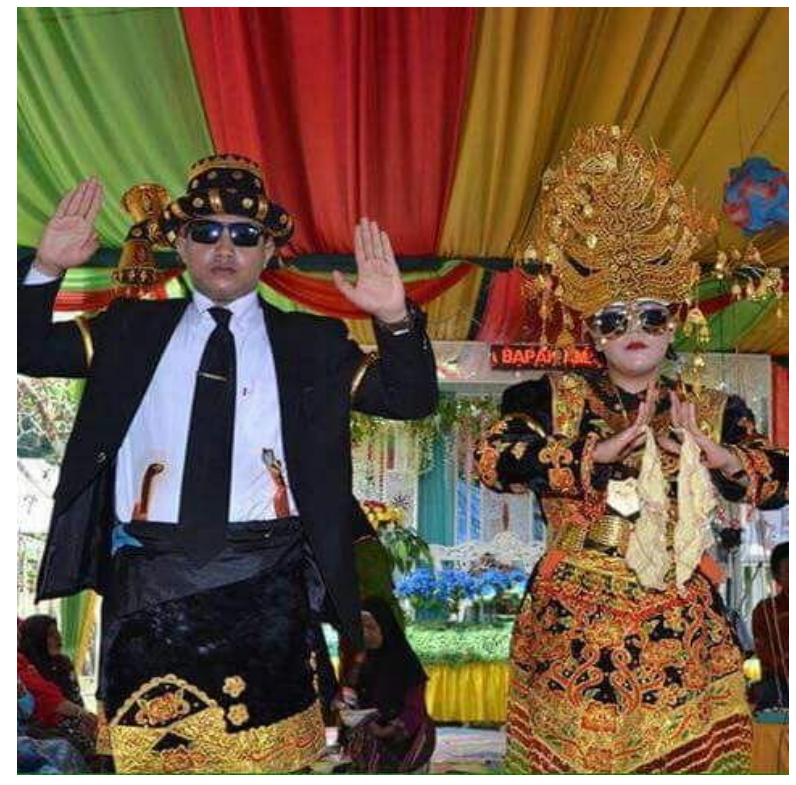

Figure 2. Tor-tor Pengantin

A singer (paronang-onang) will sing certain onang-onang with different lyrics for each tor-tor, as described in the following translated text (lyrics) below.

TABLE 1. ONANG-ONANG LYRICS FOR TOR-TOR RAJA-RAJA/NAMORA-MORA

\begin{tabular}{|l|l|l|}
\hline \multicolumn{1}{|c|}{$\begin{array}{c}\text { Mandailing } \\
\text { Language }\end{array}$} & $\begin{array}{l}\text { Indonesian } \\
\text { Language }\end{array}$ & \multicolumn{1}{|c|}{ English } \\
\hline $\begin{array}{l}\text { Ois ale baya } \\
\text { onang! }\end{array}$ & $\begin{array}{l}\text { Hei, "Onang- } \\
\text { onang"! }\end{array}$ & $\begin{array}{l}\text { Hi, “Onang- } \\
\text { onang"! }\end{array}$ \\
\hline $\begin{array}{l}\text { Santabi sapulu } \\
\text { noli } \\
\text { marsantabi. }\end{array}$ & $\begin{array}{l}\text { Maaf sepuluh } \\
\text { kali maaf. }\end{array}$ & $\begin{array}{l}\text { Forgive us } \\
\text { many times. }\end{array}$ \\
\hline $\begin{array}{l}\text { Diaraja na dao } \\
\text { dot nadonok. }\end{array}$ & $\begin{array}{l}\text { Di raja yang } \\
\text { jauh dan raja } \\
\text { yang dekat. }\end{array}$ & $\begin{array}{l}\text { Near and far } \\
\text { kings. }\end{array}$ \\
\hline $\begin{array}{l}\text { Habang siorkor } \\
\text { na songgop di } \\
\text { ayu ara. }\end{array}$ & $\begin{array}{l}\text { Terbang } \\
\text { burung siorkor } \\
\text { yang hinggap di } \\
\text { kayu besar. }\end{array}$ & $\begin{array}{l}\text { Fly the } \\
\text { sparrow } \\
\text { and perch } \\
\text { on the big } \\
\text { branch. }\end{array}$ \\
\hline $\begin{array}{l}\text { On mada raja } \\
\text { namanortor. }\end{array}$ & $\begin{array}{l}\text { Inilah raja yang } \\
\text { menortor. }\end{array}$ & $\begin{array}{l}\text { These are } \\
\text { the dancing } \\
\text { kings (doing } \\
\text { tor-tor } \\
\text { dance). }\end{array}$ \\
\hline $\begin{array}{l}\text { Tor-tor ni raja- } \\
\text { raja. }\end{array}$ & $\begin{array}{l}\text { Tor-tor untuk } \\
\text { raja-raja }\end{array}$ & $\begin{array}{l}\text { The dance } \\
\text { for the } \\
\text { kings. }\end{array}$ \\
\hline
\end{tabular}

TABLE 2. ONANG-ONANG LYRICS FOR TOR-TOR

NAPOSO/

NAULI BULUNG

\begin{tabular}{|c|c|c|}
\hline $\begin{array}{l}\text { Mandailing } \\
\text { Language }\end{array}$ & $\begin{array}{c}\text { Indonesian } \\
\text { Language }\end{array}$ & English \\
\hline $\begin{array}{l}\text { Ois onang baya } \\
\text { onang! }\end{array}$ & $\begin{array}{l}\text { Hei, "Onang- } \\
\text { onang"! }\end{array}$ & $\begin{array}{l}\mathrm{Hi} \text { "Onang- } \\
\text { onang"! }\end{array}$ \\
\hline $\begin{array}{l}\text { On male baya } \\
\text { iba nai tor-tor } \\
\text { nauli bulung } \\
\text { naposo bulung. }\end{array}$ & $\begin{array}{l}\text { Inilah Tor-tor } \\
\text { Nauli Bulung } \\
\text { (woman) dan } \\
\text { Naposo } \\
\text { Bulung } \\
\text { (man) }\end{array}$ & $\begin{array}{lr}\text { This is Tor- } \\
\text { tor Nauli } \\
\text { Bulung and } \\
\text { Naposo } \\
\text { Bulung. }\end{array}$ \\
\hline \begin{tabular}{lr}
\multicolumn{2}{l}{ Namanortor } \\
bayo & bayo \\
Sution & na \\
disembar & boru \\
Lubis. &
\end{tabular} & $\begin{array}{l}\text { Yang } \\
\text { menortor } \\
\text { laki-laki dari } \\
\text { marga } \\
\text { Nasution } \\
\text { pasangannya } \\
\text { perempuan } \\
\text { marga Lubis. }\end{array}$ & $\begin{array}{l}\text { The dancing } \\
\text { man is } \\
\text { Nasution } \\
\text { together with } \\
\text { his friend is } \\
\text { Lubis. }\end{array}$ \\
\hline $\begin{array}{l}\text { Namanyembar } \\
\text { bayo } \\
\text { Matondang na } \\
\text { disembar boru } \\
\text { Pulungan. }\end{array}$ & $\begin{array}{l}\text { Yang } \\
\text { menortor } \\
\text { laki-laki } \\
\text { Matondang } \\
\text { pasangannya } \\
\text { perempuan } \\
\text { marga } \\
\text { Pulungan. } \\
\end{array}$ & $\begin{array}{l}\text { Followed by } \\
\text { another } \\
\text { dancing man } \\
\text { is Matondang } \\
\text { and the } \\
\text { dancing } \\
\text { woman is } \\
\text { Pulungan. }\end{array}$ \\
\hline $\begin{array}{l}\text { Sarop tu jae } \\
\text { amu sarop tu } \\
\text { julu on. }\end{array}$ & $\begin{array}{l}\text { Sama-sama } \\
\text { ke hulu dan } \\
\text { ke hilir. }\end{array}$ & $\begin{array}{l}\text { Together go } \\
\text { upstream and } \\
\text { downstream. }\end{array}$ \\
\hline $\begin{array}{l}\text { Sada boru suti } \\
\text { dot boru lubis } \\
\text { on. }\end{array}$ & $\begin{array}{l}\text { Perempuan } \\
\text { marga } \\
\text { Nasution dan } \\
\text { marga Lubis. }\end{array}$ & $\begin{array}{l}\text { The women } \\
\text { are Nasution } \\
\text { and Lubis. }\end{array}$ \\
\hline $\begin{array}{l}\text { Mala git ke tu } \\
\text { jae dot tu julu } \\
\text { tola. }\end{array}$ & $\begin{array}{l}\text { Mau ke hilir } \\
\text { dan mudik } \\
\text { boleh. }\end{array}$ & $\begin{array}{l}\text { Let's go } \\
\text { upstream and } \\
\text { downstream } \\
\text { together. }\end{array}$ \\
\hline $\begin{array}{l}\text { Tapi mangizin } \\
\text { jolo tu ayah dot } \\
\text { umak. }\end{array}$ & $\begin{array}{l}\text { Tetapi harus } \\
\text { meminta izin } \\
\text { kepada ayah } \\
\text { dan ibu. }\end{array}$ & $\begin{array}{l}\text { But let's beg } \\
\text { for our } \\
\text { parents' } \\
\text { agreement. }\end{array}$ \\
\hline $\begin{array}{l}\text { Di jago harga } \\
\text { diri }\end{array}$ & $\begin{array}{l}\text { Dijaga nama } \\
\text { baik. }\end{array}$ & $\begin{array}{l}\text { Always keep } \\
\text { the family's } \\
\text { good name. }\end{array}$ \\
\hline $\begin{array}{l}\text { Tapi adong nari } \\
\text { na dilarang } \\
\text { pemerintahon. }\end{array}$ & $\begin{array}{l}\text { Tetapi } \\
\text { sekarang ada } \\
\text { yang dilarang } \\
\text { pemerintah. }\end{array}$ & $\begin{array}{l}\text { There are } \\
\text { some } \\
\text { forbidden by } \\
\text { the } \\
\text { government }\end{array}$ \\
\hline $\begin{array}{l}\text { Ulang kamu } \\
\text { marmabuk- }\end{array}$ & $\begin{array}{l}\text { Jangan kalian } \\
\text { bermabuk- }\end{array}$ & $\begin{array}{l}\text { Do not get } \\
\text { drunk. }\end{array}$ \\
\hline
\end{tabular}




\begin{tabular}{|l|l|l|}
\hline mabuk on. & mabukan. & \\
\hline $\begin{array}{l}\text { Ulang muse } \\
\text { baya } \\
\text { marjudion. }\end{array}$ & $\begin{array}{l}\text { Jangan } \\
\text { berjudi. }\end{array}$ & $\begin{array}{l}\text { Do not } \\
\text { gamble. }\end{array}$ \\
\hline $\begin{array}{l}\text { Ulang muse } \\
\text { baya } \\
\text { marnarkobaon. }\end{array}$ & $\begin{array}{l}\text { Juga tidak } \\
\text { boleh } \\
\text { mengisap } \\
\text { narkoba). }\end{array}$ & $\begin{array}{l}\text { Do not take } \\
\text { drugs. }\end{array}$ \\
\hline
\end{tabular}

TABLE 3. ONANG-ONANG LYRICS FOR ANDOR SOAYU

\begin{tabular}{|c|c|c|}
\hline $\begin{array}{c}\text { Mandailing } \\
\text { Language }\end{array}$ & $\begin{array}{c}\text { Indonesian } \\
\text { Language }\end{array}$ & English \\
\hline $\begin{array}{l}\text { Ois onang baya } \\
\text { onang! }\end{array}$ & $\begin{array}{l}\text { Hei, "Onang- } \\
\text { onang"! }\end{array}$ & $\begin{array}{l}\mathrm{Hi} \text {, "Onang- } \\
\text { onang"! }\end{array}$ \\
\hline $\begin{array}{l}\text { Parjolo ami } \\
\text { marsantabion. }\end{array}$ & $\begin{array}{l}\text { Di awal kami } \\
\text { minta maaf. }\end{array}$ & $\begin{array}{l}\text { Firstly, } \\
\text { please } \\
\text { forgive us. }\end{array}$ \\
\hline Diraja-raja on. & $\begin{array}{l}\text { Kepada raja- } \\
\text { raja }\end{array}$ & $\begin{array}{l}\text { For the } \\
\text { kings }\end{array}$ \\
\hline $\begin{array}{l}\text { Raja nadao raja } \\
\text { nadonoko. }\end{array}$ & $\begin{array}{l}\text { Raja yang jauh } \\
\text { dan raja yang } \\
\text { dekat }\end{array}$ & Far and near \\
\hline $\begin{array}{l}\text { Tarlobi-lobi } \\
\text { Raja dibagas na } \\
\text { godangon. }\end{array}$ & $\begin{array}{l}\text { Terlebih } \\
\text { kepada raja } \\
\text { yang berada } \\
\text { dirumah besar } \\
\text { ini }\end{array}$ & $\begin{array}{l}\text { Especially } \\
\text { for the king } \\
\text { of this house }\end{array}$ \\
\hline $\begin{array}{l}\text { Onma ibanai } \\
\text { tor-tor Andor } \\
\text { Soayu on. }\end{array}$ & $\begin{array}{l}\text { Inilah tor-tor } \\
\text { Andor Soayu }\end{array}$ & $\begin{array}{l}\text { This is tor- } \\
\text { tor Andor } \\
\text { Soayu }\end{array}$ \\
\hline $\begin{array}{l}\text { Bayu Suti } \\
\text { dongan ni boru } \\
\text { Lubis on. }\end{array}$ & $\begin{array}{l}\text { Laki-laki } \\
\text { marga } \\
\text { Nasution } \\
\text { berpasangan } \\
\text { dengan } \\
\text { perempuan } \\
\text { marga Lubis. }\end{array}$ & $\begin{array}{l}\text { The man is } \\
\text { Nasution } \\
\text { and his } \\
\text { couple is } \\
\text { Lubis }\end{array}$ \\
\hline $\begin{array}{l}\text { Bayo Pulungan } \\
\text { dongan ni boru } \\
\text { Hasibuan on. }\end{array}$ & $\begin{array}{l}\text { Laki-laki } \\
\text { marga } \\
\text { Pulungan } \\
\text { berpasangan } \\
\text { dengan } \\
\text { perempuan } \\
\text { marga } \\
\text { Hasibuan. } \\
\end{array}$ & $\begin{array}{l}\text { Other man is } \\
\text { Pulungan } \\
\text { and his } \\
\text { couple is } \\
\text { Hasibuan. }\end{array}$ \\
\hline $\begin{array}{l}\text { Bayo } \\
\text { Matondang } \\
\text { dongan ni boru }\end{array}$ & $\begin{array}{l}\text { Laki-laki marga } \\
\text { Matondang } \\
\text { berpasangan }\end{array}$ & $\begin{array}{l}\text { And another } \\
\text { is } \\
\text { Matondang }\end{array}$ \\
\hline
\end{tabular}

\begin{tabular}{|l|l|l|}
\hline Pulungan. & $\begin{array}{l}\text { dengan } \\
\text { perempuan } \\
\text { boru Pulungan }\end{array}$ & $\begin{array}{l}\text { and his } \\
\text { couple is } \\
\text { Pulungan. }\end{array}$ \\
\hline $\begin{array}{l}\text { Hei Onang- } \\
\text { onang }\end{array}$ & $\begin{array}{l}\text { Hei, "Onang- } \\
\text { onang"! }\end{array}$ & $\begin{array}{l}\text { Hi, "Onang- } \\
\text { onang"! }\end{array}$ \\
\hline
\end{tabular}

\section{TABLE 4. ONANG-ONANG LYRICS FOR} TOR-TOR PENGANTIN

\begin{tabular}{|c|c|c|}
\hline $\begin{array}{c}\text { Mandailing } \\
\text { Language }\end{array}$ & $\begin{array}{c}\text { Indonesian } \\
\text { Language }\end{array}$ & English \\
\hline $\begin{array}{l}\text { Ile onang baya } \\
\text { onang. }\end{array}$ & $\begin{array}{l}\text { Hei, "Onang- } \\
\text { onang"! }\end{array}$ & $\begin{array}{l}\mathrm{Hi} \text { "Onang- } \\
\text { onang"! }\end{array}$ \\
\hline $\begin{array}{l}\text { Tapuka ma le } \\
\text { tajolo mulai on. }\end{array}$ & $\begin{array}{l}\text { Mulailah kita } \\
\text { buka dulu ini. }\end{array}$ & $\begin{array}{l}\text { Let's open } \\
\text { the ceremony } \\
\text { first. }\end{array}$ \\
\hline $\begin{array}{ll}\text { Inda asok ma } \\
\text { jolo le pikiri } \\
\text { ada. }\end{array}$ & $\begin{array}{l}\text { Pelan- pelan } \\
\text { kita pikiri. }\end{array}$ & $\begin{array}{l}\text { Think } \\
\text { carefully. }\end{array}$ \\
\hline $\begin{array}{l}\text { Ulang inda } \\
\text { maruba nian } \\
\text { ale luai on. }\end{array}$ & $\begin{array}{l}\text { Janganlah } \\
\text { hendaknya } \\
\text { ada berubah. }\end{array}$ & $\begin{array}{l}\text { Hopefully, } \\
\text { everything } \\
\text { will carry on } \\
\text { well. }\end{array}$ \\
\hline $\begin{array}{lr}\text { Sian } & \text { najolo } \\
\text { indu inda } & \text { sannari on. }\end{array}$ & $\begin{array}{l}\text { Dari dulu } \\
\text { sampai } \\
\text { sekarang. }\end{array}$ & $\begin{array}{l}\text { From past to } \\
\text { present. }\end{array}$ \\
\hline $\begin{array}{l}\text { Sattabi inda } \\
\text { jolo sappulu on. }\end{array}$ & $\begin{array}{l}\text { Maaf terlebih } \\
\text { dahulu } \\
\text { sepuluh kali } \\
\text { maaf. }\end{array}$ & $\begin{array}{l}\text { Firstly, } \\
\text { forgive us } \\
\text { many times. }\end{array}$ \\
\hline $\begin{array}{l}\text { Sappulu noli } \\
\text { marsattabi on. }\end{array}$ & $\begin{array}{l}\text { Sepuluh kali } \\
\text { mohon maaf. }\end{array}$ & $\begin{array}{l}\text { Forgive us } \\
\text { many times. }\end{array}$ \\
\hline $\begin{array}{l}\text { Tu jolo na dua } \\
\text { le tolu on. }\end{array}$ & \begin{tabular}{l}
\multicolumn{2}{l}{ Kehadapan } \\
dua tiga \\
(seluruh \\
kerabat yang \\
hadir). \\
\end{tabular} & $\begin{array}{l}\begin{array}{l}\text { Toward } \\
\text { two, } \\
\text { three } \\
\text { coming } \\
\text { families). }\end{array} \\
\end{array}$ \\
\hline $\begin{array}{l}\text { Lobi inda } \\
\text { tarpasangapi } \\
\text { on ois inda } \\
\text { taronang ale } \\
\text { baya onang. }\end{array}$ & $\begin{array}{l}\text { Terlebih- } \\
\text { lebih } \\
\text { kehadapan } \\
\text { yang } \\
\text { dihormati. }\end{array}$ & $\begin{array}{l}\text { Especially for } \\
\text { the honoured } \\
\text { one. }\end{array}$ \\
\hline $\begin{array}{l}\text { Ille onang baya } \\
\text { onang. }\end{array}$ & $\begin{array}{l}\text { Hei, "Onang- } \\
\text { onang"! }\end{array}$ & $\begin{array}{l}\mathrm{Hi} \text { "Onang- } \\
\text { onang"! }\end{array}$ \\
\hline $\begin{array}{l}\text { On ma hape ni } \\
\text { nietti. }\end{array}$ & $\begin{array}{l}\text { Inilah maksud } \\
\text { dari niat kami. }\end{array}$ & $\begin{array}{l}\text { It is what we } \\
\text { intend to. }\end{array}$ \\
\hline $\begin{array}{l}\text { Haroro inda } \\
\text { paronang } \\
\text { parumaen on. }\end{array}$ & $\begin{array}{l}\text { Menyambut } \\
\text { kedatangan } \\
\text { dari menantu } \\
\text { perempuan } \\
\text { kami" } \\
\end{array}$ & $\begin{array}{l}\text { Welcoming } \\
\text { our daughter- } \\
\text { in-law. }\end{array}$ \\
\hline $\begin{array}{l}\text { Parumaen sian } \\
\text { Dolok } \quad \text { Saribu }\end{array}$ & $\begin{array}{l}\text { Menantu dari } \\
\text { Dolok Saribu. }\end{array}$ & $\begin{array}{l}\text { From Dolok } \\
\text { Saribu. }\end{array}$ \\
\hline
\end{tabular}




\begin{tabular}{|c|c|c|}
\hline on. & & \\
\hline $\begin{array}{l}\text { Parumaen } \\
\text { siakkaan on. }\end{array}$ & $\begin{array}{l}\text { Menantu } \\
\text { perempuan } \\
\text { dari anak laki- } \\
\text { laki tertua. }\end{array}$ & $\begin{array}{l}\text { The oldest } \\
\text { son's wife. }\end{array}$ \\
\hline $\begin{array}{l}\text { Ois inda } \\
\text { taronang ale } \\
\text { baya onang. }\end{array}$ & $\begin{array}{l}\text { Hei, "Onang- } \\
\text { onang"! }\end{array}$ & $\begin{array}{l}\mathrm{Hi} \text { "Onang- } \\
\text { onang"! }\end{array}$ \\
\hline $\begin{array}{l}\text { Ille onang baya } \\
\text { onang. }\end{array}$ & $\begin{array}{l}\text { Hei, "Onang- } \\
\text { onang"! }\end{array}$ & $\begin{array}{l}\mathrm{Hi} \text { "Onang- } \\
\text { onang"! }\end{array}$ \\
\hline $\begin{array}{l}\text { Haroro baya } \\
\text { raja nagodang } \\
\text { on. }\end{array}$ & $\begin{array}{l}\text { Kedatangan } \\
\text { raja yang } \\
\text { besar ini. }\end{array}$ & $\begin{array}{l}\text { The coming } \\
\text { of great king. }\end{array}$ \\
\hline $\begin{array}{l}\text { Naro sian dolok } \\
\text { saribu on }\end{array}$ & $\begin{array}{lr}\text { Yang } & \text { datang } \\
\text { dari } & \text { Dolok } \\
\text { Saribu. } & \end{array}$ & $\begin{array}{l}\text { From Dolok } \\
\text { Saribu. }\end{array}$ \\
\hline $\begin{array}{l}\text { On mada le } \\
\text { inda mora } \\
\text { name on. }\end{array}$ & $\begin{array}{l}\text { Inilah mora } \\
\text { kami ini. }\end{array}$ & $\begin{array}{l}\text { She is our } \\
\text { Mora. }\end{array}$ \\
\hline $\begin{array}{l}\mathrm{Na} \text { maroban } \\
\text { holong ni roha }\end{array}$ & $\begin{array}{l}\text { Yang } \\
\text { membawa } \\
\text { kesenangan di } \\
\text { hati" }\end{array}$ & $\begin{array}{l}\text { Who brings } \\
\text { happiness. }\end{array}$ \\
\hline $\begin{array}{l}\text { Ois inda } \\
\text { taronang ale } \\
\text { baya onang }\end{array}$ & $\begin{array}{l}\text { Hei, "Onang- } \\
\text { onang"! }\end{array}$ & $\begin{array}{l}\mathrm{Hi} \text { "Onang- } \\
\text { onang"! }\end{array}$ \\
\hline
\end{tabular}

The attributes used and the lyrics found in each tor-tor reflects that the Mandailing honor their custom very much in their life. It also indicates that custom influences the existing traditional activities.

\section{2) Kinship System}

Dalihan Na Tolu (the triangle system) is a basic framework for Mandailing kinship system. It is symbolized as three furnaces which have the same position and support each other, as illustrated in the following.

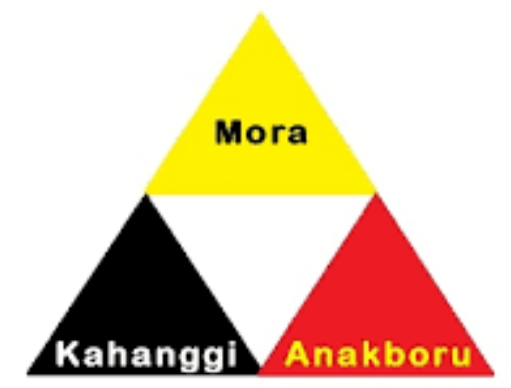

Figure 3. Framework of Dalihan Natolu
Based in the figure above, it can be seen that there are 3 (three) main groups positioned, they are mora (the party who receives the wife), kahanggi (the same clan) and anak boru (those who give wife).It describes the existence of family attachment among different addresses. These three groups are expected to live peacefully (Markoum Marsisolkot). If one of them cannot join a traditional activity; it cannot be done. It means that those three groups have the same dignity. It can be seen from the onang-onang lyrics found mostly in tor-tor pengantin.

\section{B. Local Wisdom}

Ref. [1] The role of local wisdom that critically changing and shaping global culture becomes meaningful and appropriate to the social and cultural life. It means that empowering local culture, for instance onang-onang will sustain the local wisdom. All onang-onang lyrics contain of local wisdom values; obedience, equality, respect, being humble, togetherness and carefulness, as described in the following lyrics.

\begin{tabular}{|c|c|c|}
\hline $\begin{array}{l}\text { Mandailing } \\
\text { Language }\end{array}$ & $\begin{array}{c}\text { Indonesian } \\
\text { Language }\end{array}$ & English \\
\hline $\begin{array}{ll}\text { Inda } & \text { asok ma } \\
\text { jolo le pikiri } \\
\text { ada. }\end{array}$ & $\begin{array}{l}\text { Pelan- pelan } \\
\text { kita pikiri. }\end{array}$ & $\begin{array}{l}\text { Think } \\
\text { carefully. }\end{array}$ \\
\hline $\begin{array}{l}\text { Ulang inda } \\
\text { maruba nian } \\
\text { ale luai on. }\end{array}$ & $\begin{array}{l}\text { Janganlah } \\
\text { hendaknya } \\
\text { ada berubah. }\end{array}$ & $\begin{array}{l}\text { Hopefully, } \\
\text { everything } \\
\text { will carry c } \\
\text { well. }\end{array}$ \\
\hline $\begin{array}{l}\text { Sattabi inda } \\
\text { jolo sappulu }\end{array}$ & $\begin{array}{l}\text { Maaf terlebih } \\
\text { dahulu }\end{array}$ & $\begin{array}{l}\text { Firstly, } \\
\text { forgive }\end{array}$ \\
\hline on. & $\begin{array}{l}\text { sepuluh kali } \\
\text { maaf. }\end{array}$ & many times \\
\hline $\begin{array}{l}\text { Lobi inda } \\
\text { tarpasangapi }\end{array}$ & $\begin{array}{l}\text { Terlebih- } \\
\text { lebih }\end{array}$ & $\begin{array}{l}\text { Especially } \\
\text { the }\end{array}$ \\
\hline $\begin{array}{lr}\text { on ois inda } \\
\text { taronang ale }\end{array}$ & kehadapan & $\begin{array}{l}\text { honoured } \\
\text { one. }\end{array}$ \\
\hline
\end{tabular}

The lyrics found in tor-tor pengantin think carefully emphasize the imprtance of carefulness in life in order to get what is intended to; Firstly, forgive us many times reminds the Mandailing to be humble anywhere and any time; and the honoured one shows how the Mandailing respect the others.

Moreover, the lyrics of onang-onang also warn the youngters the important of obedience and 
togetherness as found in tor-tornaposo/nauli bulung below.

\begin{tabular}{|c|c|c|}
\hline $\begin{array}{l}\text { Mandailing } \\
\text { Language }\end{array}$ & $\begin{array}{c}\text { Indonesian } \\
\text { Language }\end{array}$ & English \\
\hline $\begin{array}{l}\text { Sarop tu jae } \\
\text { amu sarop tu } \\
\text { julu on. }\end{array}$ & $\begin{array}{l}\text { Sama-sama } \\
\text { ke hulu dan } \\
\text { ke hilir. }\end{array}$ & $\begin{array}{l}\text { Together go } \\
\text { upstream } \\
\text { and } \\
\text { downstream. }\end{array}$ \\
\hline $\begin{array}{l}\text { Tapi adong nari } \\
\text { na dilarang } \\
\text { pemerintahon. }\end{array}$ & $\begin{array}{l}\text { Tetapi } \\
\text { sekarang ada } \\
\text { yang } \\
\text { dilarang } \\
\text { pemerintah. }\end{array}$ & $\begin{array}{l}\text { There are } \\
\text { some } \\
\text { forbidden by } \\
\text { the } \\
\text { government }\end{array}$ \\
\hline $\begin{array}{l}\text { Ulang kamu } \\
\text { marmabuk- } \\
\text { mabuk on. }\end{array}$ & $\begin{array}{l}\text { Jangan kalian } \\
\text { bermabuk- } \\
\text { mabukan. }\end{array}$ & $\begin{array}{l}\text { Do not g } \\
\text { drunk. }\end{array}$ \\
\hline $\begin{array}{l}\text { Ulang muse } \\
\text { baya } \\
\text { marjudion. }\end{array}$ & $\begin{array}{l}\text { Jangan } \\
\text { berjudi. }\end{array}$ & $\begin{array}{l}\text { Do } \\
\text { gamble. }\end{array}$ \\
\hline $\begin{array}{l}\text { Ulang muse } \\
\text { baya } \\
\text { marnarkobaon. }\end{array}$ & $\begin{array}{l}\text { Juga tidak } \\
\text { boleh } \\
\text { mengisap } \\
\text { narkoba). }\end{array}$ & $\begin{array}{l}\text { Do not take } \\
\text { drugs. }\end{array}$ \\
\hline
\end{tabular}

The value of togetherness can be seen obviously from the lyric Together go upstream and downstream which also implies the value of equality; the word forbidden followed by the lyrics Do not get drunk, Do not gamble and Do not take drugs educated the youngters to obey all the rules decided.

The lyrics of onang-onang are always repeated many times for any types of tor-tor. If the Mandailing maintain this custom, certainly it will help to build the character of their future generations for the noble local wisdom values have been implemented in their life.

\section{Education}

Education plays the most important roles for culture and local wisdom. The elements of culture which bring the values of local wisdom can me sustained thorugh the education. Education itself does not only talk about the young generations but also all the members of society. Ref. [6] National character cannot be separated from the people who support preserving the cultural wisdom region. A good education is one of the factors supporting the creation of a national character within the individual communities. Onang-onang lyrics expressed during manortor at wedding ceremony educates the Mandailing how they appreciate their, custom, preserve the culture and realize their role. The lyrics also describe the wisdom of Mandailing family in educating their children through the oral tradition or culture.

\section{CONCLUSION}

Onang-onang is one of maintained oral traditions in Angkola Mandailing as the lyrics expressed, the attributes used and the performance done (manortor) involve the participation of the community nowdays in order to educate the young generations to sustain the local wisdom by empowering the local culture.

\section{REFERENCES}

[1] H. Jenkins," Pop Cosmopolitanism: Mapping Cultural Flows in an Age of Media Convergence in the New Millennium ". Marcelo M. Suárez-Orozco and Desirée Baolian QinHilliard University of California Press Berkeley and Los Angeles, California, 2004.

\{2\} M.L. Larson," Meaning-Based Translation: A Guide to Cross Language Equivalence". London: University Press of America, 1984.

[3] Koentjaraningrat, "Pengantar ilmu antropologi”. Jakarta: PT. Rineka Cipta, 1990.

[4] P. Nasution, "Adat Budaya Mandailing dalam Tantangan Zaman.. Medan: Forkala, 2005.

[5] R. Sibarani, "Kearifan lokal: hakikat, peran, dan metode tradisi lisan",. Jakarta: ATL, 2012.

[6] S. Muchlas and Hariyanto. "Concepts and models of Character Education". Bandung: Remaja Rosdakarya, 2011. 